\title{
The Current Situation of Social Work Activities in Hospitals in Vietnam
}

\author{
Dr. Nguyen Trung Hai ${ }^{1}$, Dr. Nguyen Thi Hoai $\mathrm{An}^{2}$ \\ ${ }^{1,2}$ University of Labor and Social Affairs, Vietnam \\ 43 Trần Duy Hưng - Trung Hòa - Cầu Giấy - Hà Nội - Tel :043.5564584 - Fax:043.5564584
}

\begin{abstract}
ABTRACT: Since the Prime Minister signed the decision approving the project 32/2010 on March, 25, 2010 "Development of Social Work Profession in Vietnam in the period of 2010 - 2020", social work has strongly developed in many different areas including the medical field. Specifically, the Ministry of Health approved the project "Development of the Social Work profession in the health sector from 2011 through 2020" and the Circular 43/2015 on "The social work activities in the hospitals and the organizational form to perform the social work activities in hospitals". These documents are fundamental to carry out social work activities in hospitals. However, this is a new field so the implementation of these activities is still difficult and lacks detailed supporting guidelines. This study was conducted to assess the status of the five main activities of social workers in hospitals regulated under Circular 43/2015, thereby providing solutions to improve the effectiveness of social work activities.
\end{abstract}

KEY WORDS: Medical Staff, Patients, Social Work in a Hospital, Social Work Activities

\section{INTRODUCTION OF THE STUDY}

Social work plays an important role in building a harmonious relationship between the physical and mental health of patients, between patients and relatives, between patients and doctors, and with medical facilities and the community they serve. Effective social work activities in hospitals will contribute to change awareness and promote positive behavior, prevent and mitigate negative impacts affecting interpersonal relationships, create favorable working conditions and improved efficiency results in medical examinations and effective treatment for whatever the doctors find out is wrong with you.

Recognizing the gravity of the above problems, there have been many policies and guidelines developed by the Ministry of Health to connect and bring social work into hospitals as Project 32 of the Prime Minister on "Development of Social Work profession in the period of 2010 - 2020." And the Project on "Development of Social Work in the Health Sector for the period of 2011-2020" of the Ministry of Health. Most recently, in 2015, the Ministry of Health issued the Circular 43/2015 regulating the tasks of social work in hospitals and the form of organizing the implementation of social tasks in hospitals.

The positive effects of Social work activities have increasingly proved the importance of this field. However, these activities are still at the beginning stages because there is a lack of formal scientific background as well as professional training programs for social workers in this area. Stemming from the above practical issues, this article will introduce the study of "The situation of social work activities in hospitals". The results of the study will be for us to see more clearly the scientific evidence to prove the effectiveness of social work in the hospitals of Vietnam.

\section{Objectives of the study}

The study assessed the current status of social work activities in the hospital and analyzes the factors affecting the effectiveness of these activities and provides solutions to improve the effectiveness of social work activities in the hospitals of Vietnam.

\section{Research scope}

- Content: Research, evaluation and analysis of five social work activities in hospitals under Circular 43/2015 of the Ministry of Health, Viet Nam

- Time: from 2015 to 2018

- Scope of the area: Research conducted in some Hanoi area hospitals with social workrooms/teams. Specifically, (1) The Institute of Pediatrics, (2) Bach Mai Hospital, (3) K Hospital, (4) 108 Military Hospital, (5) Phu Tho General Hospital. 


\section{International Journal of Current Science Research and Review}

ISSN: 2581-8341

Volume 05 Issue 01 January 2022

DOI: 10.47191/ijesrr/V5-i1-04, Impact Factor: 5.825

IJCSRR@ 2022

www.ijcsrr.org

\section{Research Methods}

Methods of researching documents/desk review: to study relevant documents including policy documents, case management records in social work departments in hospitals...etc to know about the need for Social Work activities in hospitals around the world and in Vietnam.

\section{In-depth interview method}

The research collected and analyzed specific information related to research subjects, study about the implementation of social work activities in hospitals as well as the needs and concerns of this target group. Total number of participants in these in-depth interviews included 5 patients at each of the above selected hospitals to find out about their needs and desires, 15 social workers , 5 doctors/nurses and 3 managers in each of the five selected hospitals to learn about the situation of social work activities being implemented and see how effectively these activities and their wishes for enhancing social work activities are being carried out, and to learn about the impact factors as well as solutions to improve operational efficiency.

\section{Group discussion method}

The study conducted a group discussion with the participation of social work staff currently working at each of the five selected hospitals to discuss in-depth issues and provide solutions to improve the effectiveness of social work activities in the hospital.

\section{Method of questionnaires survey}

The questionnaire method to collect information through conducting a direct interview with the target of research to describe a policy of the needs for subjects and the status of social work services in the hospital's demands being met. Questionnaire surveys with 40 social workers currently working in five selected hospitals were conducted. Each hospital randomly selected 8 social workers according to the list of rooms. These social workers have different fields experience, working time and qualifications to obtain objective and multifaceted assessments of the effectiveness of social work activities implemented in hospitals.

\section{Data analysis method}

Data collected through a survey of questionnaires, research using synthesis and analysis methods ... Using SPSS 23.0 tool to analyze collected questionnaires from excel software to visualization data and provide an overall picture of social work activities in the hospital.

\section{FINDINGS OF STUDY}

The study showed that most hospitals in the country, especially hospitals in the central region of Vietnam are often overloaded. Health workers do not have enough time and ability to solve many urgent needs of patients, such as instructions or an explanation of the medical treatment process, counseling on treatment regimens, ways to prevent illness, psychological support, exploring information on social demographic characteristics of patients, etc. This situation is causing many troubles for patients such as the lack of information when accessing and using medical services, the dissatisfaction of patients with health facilities, etc.

Improved social work activities in the hospitals of Vietnam will help the working relationships of health workers, patients, and their relatives to get better. This study was to describe the situation, evaluate and analyze specifics for the effectiveness of social work activities in five selected hospitals based on the Health Ministry's Circular 43/2015.

Table 1: Frequency of implementing social work activities in hospitals

\begin{tabular}{|l|l|l|l|l|}
\hline No & Social work activities in hospitals & Regularly (\%) & Sometimes (\%) & Never (\%) \\
\hline 1. & Support and consulting on solving social work issues & 46.7 & 42.1 & 11.2 \\
\hline 2. & $\begin{array}{l}\text { Information, communication , and law dissemination } \\
\text { and education }\end{array}$ & 78.5 & 21.5 & 0 \\
\hline 3. & Mobilization and receiving support/aids & 87.8 & 12.2 & 0 \\
\hline 4. & Support health providers & 45.8 & 39.2 & 15 \\
\hline 5. & Training and retraining in social work & 32.1 & 41.7 & 26.2 \\
\hline
\end{tabular}

Sources: Survey results of research on Social work activities in hospitals, 2018 


\title{
International Journal of Current Science Research and Review
}

\author{
ISSN: 2581-8341
}

\section{Volume 05 Issue 01 January 2022}

DOI: 10.47191/ijcsrr/V5-i1-04, Impact Factor: 5.825

IJCSRR@ 2022

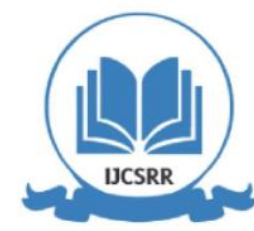

Www.ijcsrr.org

The results of table 1 showed that the five activities of social workers in the five selected hospitals are regularly implemented as providing information, communication and law dissemination, legislation education, mobilizing, supporting health providers and in the training and retraining of the staff in social work. These activities helps the hospitals to-receive funding from government agencies, non-government organizations and people's kindness. The first two activities are quite suitable for social workers and they are activities that the hospital expects social workers to implement to support patients. Because the need for funding, communication and information are indispensable for the patients, the medical staff and the hospitals. Social workers are implementing these communication activities in order to provide dissemination of necessary information for patients to receive their benefits related to a medical examination as well as insurance money, and their treatment.

The activities that social workers have not done much are activities that require deep expertise as well as require a large number of social workers. Specifically, activities that have not been much implemented as training and retraining in the field of social work; organizing a team of collaborators to work on social work in hospitals and organizing charitable activities, in the hospitals and in the surrounding community.

For activities that are often performed or sometimes infrequently performed, it is necessary to have assessments, to learn about what difficulties the social workers, the patients and the medical staff have in the process of implementation so that managers can analyze how to raise higher efficiency of these activities in supporting those in need in hospitals.

The following data are analyzed based on the assessment of social workers who perform the above activities. The level of difficulty in implementing these activities and the impact factors are affecting these difficulties, thereby giving managers the recommended solutions to improve the efficiency of these activities.

\subsection{Supporting and counseling on solving social work issues for patients and family members in the process of medical examination and treatment}

This activity is understood that social workers will perform tasks such as counseling, providing information on policies, regulations of hospitals for patients and family members. The content of social work activities dealing with social work problems for patients is related to the tasks of implementation to support patients and family members in all 3 aspects: before treatment - in the process of treatment - after treatment.

Specifically, before treatment, social workers must initially screen patients and families, to find out who is most in need and what specifically do they need, then provide emergency assistance and expedite treatment; perform an overall psychosocial assessment for patients; educating patients and families about different diseases and treatment options, the consequences and reactions of various possible treatments; the consequences of refusing treatment; their rights, policies, and services in the community. Support patients and family members in making decisions related to treatment, insurance, benefits ... In some cases regarding treatment, social workers have a direct intervention role in emergency cases, they may diagnose mental health problems related to physical illness or specialized mental health problems, they may conduct direct therapy or referrals, help patients and family members in the hospital, transfer to other doctors or departments and in the case of necessity, explain to the patients information on hospital rules. After treatment, social workers perform the task of coordinating of discharge, building community care plans, coordinating disease prevention support, and educating family members about access to health care services in the community, etc.

Table 2: Contents of Supporting and Counseling on Social Work Issues

\begin{tabular}{|c|l|l|l|l|}
\hline No & $\begin{array}{l}\text { Content of supporting and counseling } \\
\text { social work issues }\end{array}$ & $\begin{array}{l}\text { Not difficulty } \\
(\boldsymbol{\%})\end{array}$ & $\begin{array}{l}\text { Normal } \\
(\%)\end{array}$ & $\begin{array}{l}\text { Difficulty } \\
(\%)\end{array}$ \\
\hline 1. & $\begin{array}{l}\text { Welcoming, giving instructions, providing information and } \\
\text { introducing medical examination and treatment services }\end{array}$ & 78.4 & 21.6 & 0 \\
\hline 2. & The organization caring for patients and their relatives & 68.7 & 31.3 & 0 \\
\hline 3. & Supporting emergency social work activities for patients & 25.7 & 46.9 & 27.4 \\
\hline 4. & $\begin{array}{l}\text { Support and advise patients on the rights, legitimate } \\
\text { interests and obligations of patients, programs and policies } \\
\text { in medical examination ,and treatment }\end{array}$ & 35.8 & 58.2 & 16 \\
\hline
\end{tabular}




\section{International Journal of Current Science Research and Review}

ISSN: 2581-8341

Volume 05 Issue 01 January 2022

DOI: 10.47191/ijesrr/V5-i1-04, Impact Factor: 5.825

IJCSRR@ 2022

www.ijcsrr.org

\begin{tabular}{|c|l|l|l|l|}
\hline 5. & $\begin{array}{l}\text { Providing information and advice to patients who have } \\
\text { designated medical examination and treatment facilities or } \\
\text { discharged from hospitals; Supporting discharge procedures } \\
\text { and referring patients to support locations in the community }\end{array}$ & 41.5 & 9.3 \\
\hline 6. & $\begin{array}{l}\text { Coordinating and guiding organizations and volunteers who } \\
\text { wish to implement and support the social work of hospitals }\end{array}$ & 57.2 & 36.3 & 6.5 \\
\hline
\end{tabular}

Sources: Survey results of Research on social work activities in the hospital, 2018

The first two of the above listed six activities are the most frequently performed tasks of social work staff in hospitals and the people surveyed do not feel difficulty in this activity such as: reception, giving instructions, providing information and introducing medical examination and treatment services of the hospital for the patients as they entered the examination section or clinic; talking with patients and their relatives to get information about the health situation, difficult circumstances of the patients, and to determine the level and have plans to support social psychology and organization of implementation.

As presented in the previous contents, the social work profession has only been implemented in hospitals since the Circular $43 / 2015$. Because it is a new profession, social work staff surveyed shared that they encountered many difficulties in performing professional jobs. Many health workers do not understand about social work, sometimes they think social workers participate and will compete with their position. Therefore, they do not cooperate or cause difficulties for social workers. Social workers mainly do nondemanding jobs or jobs that don't require high expertise such as reception activities and providing information etc. Some other more complicated tasks as developing a social psychological support plan and implementation of organizational tasks have not been implemented much.

There are a number of tasks that social workers find difficult to implement, which are activities such as providing information and counseling for patients who have designated medical examination results, treatment or discharge facilities; supporting discharge procedures and referring patients to support locations in the community; counseling for patients on their rights, policies on health insurance and social allowances in medical examination and treatment. These are all activities that social workers can perform well and bring benefit to patients, if the social workers are well trained. However, these activities have not been well implemented so social workers need training and time to understand this information so to be able to consult patients or to provide explanations about health insurance policies and other policies should be up-to-date so that social workers have a wide range of knowledge in this area. Especially one of the limitations that almost social workers have is how to introduce patients to support points in their community. A big problem here is that the of social work staff in the hospital are not enough while the number of patients is too large. Therefore, social workers in hospitals still face many difficulties in carrying out these activities. It is an important activity that needs to be done more often to ensure the third function of social work in hospitals, which is supportive intervention after treatment.

Health workers face many difficulties when they have to carry out emergency support for patients. One part of the reason is that many of these patients are victims of domestic violence, gender violence, accidents, and disasters. When they are taken to the hospital, most of them will be approached not by social workers but by doctors or police or they can be referred to specialists if their problem is related to mental issues. Ensuring safety for the patient as supporting for psychology, social support, legal counseling, forensic assessment, mental forensics are still performed not by social workers but by other employees. Moreover, these interventions require very intensive knowledge. For example, psychological interventions with victims of violence often result in severe depression or crisis. To intervene, there must be deep psychological or mental health knowledge and long-term intervention. For the newly graduated social workers, the current training programs of social work cover the fields. However, there are not many specialized modules, especially in the mental field. As for health workers, who are willing to work in the Social Work Department, they are not trained in this field. Therefore, it is not easy for social workers to implement this type of intervention.

\subsection{Information, communication and law dissemination and education}

This activity was assessed by the social work staff at each hospital and the results are that they do not have any problems and they performed these tasks quite well. 


\section{International Journal of Current Science Research and Review}

ISSN: 2581-8341

Volume 05 Issue 01 January 2022

DOI: 10.47191/ijesrr/V5-i1-04, Impact Factor: 5.825

IJCSRR@ 2022

Www.ijcsrr.org

Table 3: Content of Information, Communication and Law Dissemination and Education

\begin{tabular}{|c|l|l|l|l|}
\hline No & $\begin{array}{l}\text { Content of information, communication and law } \\
\text { dissemination and education }\end{array}$ & $\begin{array}{l}\text { Not a difficulty } \\
(\boldsymbol{\%})\end{array}$ & $\begin{array}{l}\text { Normal } \\
(\%)\end{array}$ & $\begin{array}{l}\text { A Difficulty } \\
(\%)\end{array}$ \\
\hline 1. & $\begin{array}{l}\text { Performance the work of public relation and providing } \\
\text { information for the press }\end{array}$ & 76.8 & 7.5 \\
\hline 2. & $\begin{array}{l}\text { Develop a plan for health education communication for } \\
\text { patients and organize the implementation of the plan } \\
\text { after it is approved }\end{array}$ & 68.5 & 26.3 & 5.2 \\
\hline 3. & Development content of documents & 22.7 & 67.4 \\
\hline 4. & Update and disseminate policies and laws of the State & 35.6 & 32.9 & 31.5 \\
\hline 5. & $\begin{array}{l}\text { The organization and implementation of the code of } \\
\text { conduct, the hospital's suggestion box }\end{array}$ & 55.2 & 25.7 & 19.1 \\
\hline 6. & $\begin{array}{l}\text { Organization of cultural activities, art, physical training } \\
\text { and sports activities suitable for medical staff and } \\
\text { patients. }\end{array}$ & 63.6 & 21.7 & 14.7 \\
\hline
\end{tabular}

Source: Survey results of Research on Social work activities in hospitals, 2018

Through the information and documents of the medical team, social workers organize extensive communication and education activities to help patients get more information about their illnesses, thereby improving the effectiveness of medical examination and treatment. Specific activities are implemented as follows:

Performing the work of public relations and providing information for the press. This is not a regular job for most social workers as this is only done when the institute assigns the social workers this task. With this task, most of them focus on the content related to voluntary activities, mobilization, and sponsorship, but now social workers are really currently supporting patients. Therefore, they do not feel it is too difficult to do this work.

Develop a plan for health education communication for patients and organize the implementation of the plan after it is approved. The development of a health education communication plan for patients is not too difficult for social workers because when implementing this task, social workers often cooperate with medical staff.

Social workers do not find any difficult to carry out activities such as the development of content and materials to introduce and promote, the services and activities of hospitals to patients and communities through organizing activities, programs, events and conferences, workshop. Regularly, according to each hospital's plan, social workers must develop the content, information, and images to promote the hospital. Communicating with individuals, organizations, and communities through image materials is one of the regular tasks that social workers need to do. Here also we must emphasize the issue of coordination between functional departments if they want to do this job well such as social workers need to coordinate with administrative offices to get information and full images. If this coordination is not done well, it will be difficult to have effectiveness. Social workers suggested that they should be more active in getting information, pictures to design event programs. To do that, social work departments need to be equipped with additional equipment such as cameras, recorders etc...

Update and disseminate policies and laws of the State related to medical examination and treatment, hospital operations for health workers, patients, and family members. Updating policies and laws of the State related to medical examination and treatment is not difficult at the 4.0 industry period refers to a interconnectivity, automation, machine learning, and real-time data, smart manufacturing, smart digital technology, big data. However, to clearly understand the nature of documents to disseminate to patients and health workers, there is a need for deep professional knowledge. With health workers, the dissemination is not difficult because it can be done through hospital meetings and websites but the dissemination of information widely to patients is another problem because there is no optimal method to implement this task.

The final two activities are organizing the implementation of the code of conduct, the hospital's suggestion box; and organizing cultural and art or physical training and sports activities suitable for medical staff and patients are not difficult to implement. According to social workers, these activities are more effective if they are associated with professional activities or they can be conducted by administrative offices. 


\section{International Journal of Current Science Research and Review}

ISSN: 2581-8341

Volume 05 Issue 01 January 2022

DOI: 10.47191/ijcsrr/V5-i1-04, Impact Factor: 5.825

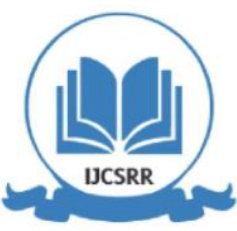

www.ijesrr.org

\subsection{Mobilizing, receiving sponsorship}

Social workers need to perform two main tasks including mobilizing resources and receiving funding from different sources to support patients. Resources can be understood as physical resources and spiritual resources but in this activity more inclined to physical resources. After mobilizing these resources, social workers need to receive resources and use them effectively. With social work models abroad, social workers are always trusted to implement activities to receive and coordinate the use of these funding sources. This is more effective and sustainable because of the philosophy and specific knowledge of social work towards fairness based on assessing the patients' real needs and providing resources towards improving their ability to solve problems. This is especially important for post-treatment support activities that require assistance for patients and families to have a more stable life.

Table 4: Mobilizing and receiving funding

\begin{tabular}{|l|l|l|l|l|}
\hline No & Mobilizing and receiving funding & $\begin{array}{l}\text { Not difficulty } \\
(\boldsymbol{\%})\end{array}$ & Normal (\%) & $\begin{array}{l}\text { Difficulty } \\
(\boldsymbol{\%})\end{array}$ \\
\hline 1. & Receiving funding & 72.5 & 16.4 & 11.1 \\
\hline 2. & Mobilizing funding & 15.4 & 33.8 & 50.8 \\
\hline
\end{tabular}

Source: Survey results of Research on Social work activities in hospitals, 2018

The results show that social workers do not face any difficulties with receiving funding from charitable individuals and organizing agencies. Difficulties will arise more when you need to mobilize other social sources or medical staff and other patients.

It is very good that social workers are the ones who receive and organize sponsorship activities because they have full and comprehensive assessments about patients. The form of mobilizing and sponsorship here is mainly implemented by social work staff through the hospital website. This is a very useful information channel, especially for large and reputable hospitals. Since most units and individuals want to carry out the sponsorship, they will actively go to the hospital's website and looking for information. If they want to go for funding directly, they need to know more information and issues to make effective funding. Social workers are flexible through maintaining active relationships with organizational agencies so that they can build up financial activities into long-term plans. It is said that sponsorship forms need more specific information or social workers can communicate with responsible people for specific assessments of patient needs and putting information on the website or other channels so that individual or organizations will sponsor more cases.

\subsection{Support for medical staffs}

The role and duty of social workers are not only limited to intervene and support for patients and families of patients but also to support psychological and social issues so as to relieve stress for the medical team. There have been many opinions and complaints in the past that the attitude and behavior of medical staff with patients and family members are too emotional and thus causing many difficulties. There are many reasons for these problems, but it can be seen that the frequent work and overburdened of work under enormous pressure is one of the major causes of excessive stress for the medical team. Therefore, the workload needs to be shared among more medical workers, thus reducing stress to improve the efficiency of communicating with patients and conducting medical examination and treatment.

Table 5: Contents of supporting medical staffs

\begin{tabular}{|c|l|l|l|l|}
\hline No & Content of supporting medical staffs & Not difficulty (\%) & Normal (\%) & $\begin{array}{l}\text { Difficulty } \\
(\%)\end{array}$ \\
\hline 1. & $\begin{array}{l}\text { Provide information about patients to medical } \\
\text { staffs in case of necessity to support treatment }\end{array}$ & 31.7 & 56.4 & 11.9 \\
\hline 2. & $\begin{array}{l}\text { Encourage and share with medical staff when } \\
\text { there are problems with patients during } \\
\text { treatment. }\end{array}$ & 25.8 & 47.3 & 26.9 \\
\hline
\end{tabular}

Source: Survey results of Research on Social work activities in hospitals, 2018 


\section{International Journal of Current Science Research and Review}

ISSN: 2581-8341

Volume 05 Issue 01 January 2022

DOI: 10.47191/ijcsrr/V5-i1-04, Impact Factor: 5.825

IJCSRR@ 2022

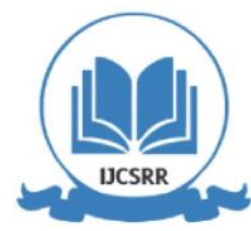

Www.ijcsrr.org

Social work staff thinks that there are not many difficulties in providing information about patients to health workers in case of the necessity to support treatment.

Another activity "Encouraging, sharing with medical staff when having problems with patients during the treatment" is well implemented with many creative plans. Besides, some hospitals can directly exchange and share information to relieve stress. In some other hospitals, social workers have actively implemented creative activities to relieve stress and pressure on the team so that they can do better jobs.

Social workers do not directly support health care workers but they indirectly help health workers greatly by answering patients' questions so that health workers have more time to concentrate on their expertise. However, the problem is that the health medical team is too crowded while the number of social workers is still limited. Therefore, the intervention and support of health workers are not adequate. Interventions for supporting health workers presently are only at the level of sharing and relieving stress while other support activities such as psychological interventions and consultations are still almost impossible to carry out. Interventions to solve the problems between patients and health workers are rarely done and mainly performed independently. Therefore, the problems are only brought up but not resolved to the root causes.

\subsection{Training and retraining in the field of social work}

One of the important activities in the field of social work is to participate in guiding the practice of social work for pupils and students of social work vocational training institutions.

Table 6: Contents of refresher training in the field of social work

\begin{tabular}{|c|l|l|l|l|}
\hline No & $\begin{array}{l}\text { Contents of refresher training in the field of } \\
\text { social work }\end{array}$ & $\begin{array}{l}\text { Not difficulty } \\
(\%)\end{array}$ & $\begin{array}{l}\text { Normal } \\
(\%)\end{array}$ & $\begin{array}{l}\text { Difficulty } \\
(\%)\end{array}$ \\
\hline 1. & $\begin{array}{l}\text { Participate in guiding the practice of social work } \\
\text { for pupils and students of social work vocational } \\
\text { training institutions }\end{array}$ & 28.5 & 34.2 & 45.4 \\
\hline 2. & $\begin{array}{l}\text { Retraining and training on social work } \\
\text { knowledge for medical staffs and hospital staffs }\end{array}$ & 15.7 & 38.9 & 21.5 \\
\hline 3. & $\begin{array}{l}\text { Coordinate training and retraining of basic } \\
\text { health knowledge for people working on social } \\
\text { work }\end{array}$ & 36.7 & 41.8 & \\
\hline
\end{tabular}

Source: Survey results of Research on Social work activities in hospitals, 2018

Implementing practical guidance activities is not only good for students and training institutions, but even social workers in hospitals can improve their knowledge through a professional exchange. However, the practice at the grassroots level still faces many difficulties with both subjective and objective reasons. It should be understood that practice is an indispensable element in social work. In the world, social work practice activities are compulsory conditions for social work institutions in general and in hospitals particularly. If a social worker does not have enough the practicum hours or practicum instructions will have to re-study and take the exam for practicing certificate. In Vietnam, we have not had sufficient specific regulations in practical activities are still limited. The other reason is too much of work for social workers is in hospitals. If there are strategies and close coordination between training institutions and hospitals to develop specific programs and guidelines, then students may participate in direct support of social workers in their activities in a hospital. Thus social workers are better able to do their jobs and through such support activities, the student will get to practices more often.

There are some difficulties for people who are working on training coordination, retraining basic knowledge for a social worker to do an effective job due to limited knowledge. In order to coordinate with other training institutions, these key people depend on funding and policy mechanisms from higher levels. One of the difficulties here is that the medical staff is very busy with their work. Another problem is organizing training for key staff but nobody comes or participation is not enthusiastic. It is vital to communicate the importance of this effort and leaders need to have a separate policy mechanism for promoting social work classes for health workers. 


\section{International Journal of Current Science Research and Review}

ISSN: 2581-8341

Volume 05 Issue 01 January 2022

DOI: 10.47191/ijcsrr/V5-i1-04, Impact Factor: 5.825

IJCSRR@ 2022

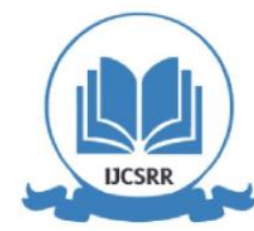

Www.ijcsrr.org

Activities on "organizing of collaborators team to do social work in hospitals" and "organizing charitable activities and social work of hospitals in the community" have not been implemented much due to limited resources. It is due to the characteristics of some hospitals such as treatment for patient's only, limited time and limited human resources so that kind of above activities are not possible. There are only a few activities that are implementing however; those are entertainment activities such as organizing activities for children on the occasion of International Children's Day at the hospital etc.

\subsection{Factors that affect social work activities in hospitals}

It can be seen that there have been many efforts; the social work staff in the hospital still face many difficulties, thereby affecting the efficiency of the work. The following table will describe and analyze specific difficulties.

Table 7: 5 Factors that negatively affect social work activities in hospitals

\begin{tabular}{|l|l|l|l|l|}
\hline No & The influencing factors & Completely right $(\boldsymbol{\%})$ & Partly right (\%) & Not right $(\%)$ \\
\hline 1. & Due to policy mechanisms & 66.8 & 20.1 & 13.1 \\
\hline 2. & Due to leadership awareness & 53.3 & 27.8 & 18.9 \\
\hline 3. & Due to low staff capacity & 78.8 & 21.2 & 0 \\
\hline 4. & $\begin{array}{l}\text { Due to lack of coordination of functional } \\
\text { departments }\end{array}$ & 31.6 & 25.8 & 42.6 \\
\hline 5. & Due to the characteristics of the patients/clients & 45.7 & 32.9 & 21.4 \\
\hline 6. & Other & 0 & 0 & 0 \\
\hline
\end{tabular}

Source: Survey results of Research of social work activities in hospitals, 2018

\section{Policies that negatively affect social worker's effectiveness}

- Lack of Policy Mechanisms The lack of good policies and the low general awareness by health workers of these policies about the role of social workers in the hospitals is the second factor that negatively affects the effectiveness of social work staff in hospitals. The result of an in-depth interview and group discussion showed that the policy directly affects the effectiveness of the work.

For policies at the national level such as the social work project in the hospital or the circular number 43 , it can be seen that the contents are macro and directed to regulate the activities of social workers to perform the tasks. However, policy makers need to pay more attention to the lives of social workers in hospitals. There is a lack of specific regulations and policies to support social workers in hospitals and this partly limits the enthusiasm and commitment of social workers in hospitals. The Ministry of Labor, Invalids and Social Affairs has issued regulations to support the medical staff in how to deal with patients. There are no other operating policies except salary for social workers in hospitals so they have to cope with many difficulties. It is easy to see that when "minds" are unstable, the effectiveness of the social workers in implementing activities will not be highly effective.

\section{- Lack of Awareness of leaders negatively affects their work's performance}

The social work profession has been developed and stepped into the society of Vietnam gradually however the perception of society about social work activities is still very limitedly. Opinions of people who participated in the survey agree that awareness by the people they work with has a great influence on the effectiveness of social work activities. It can be seen that the perception of leaders towards social workers greatly affects the performance of their work. Social workers will be given favorable conditions and a good working environment when their leaders are properly aware of the importance of social work. It is vital for the leaders to be trained or participate in seminars, and visit-model hospitals to get the appropriate and deeper understanding of the important work performed by social work professionals.

\section{- $\quad$ Low Staff capacity negatively affects social worker's performance}

The table above shows that $78.8 \%$ of the respondents agree that the low staff capacity of social workforce in hospitals is the biggest negative factor on their effectiveness, causing difficulties in implementing social activities.

In the group discussions, when discussing the importance of social work, the most common opinions agreed that the skills of social work staff play an important role, directly affecting the reduction of conflicts and the quality of support patients receive during treatment 


\section{International Journal of Current Science Research and Review}

ISSN: 2581-8341

Volume 05 Issue 01 January 2022

DOI: 10.47191/ijesrr/V5-i1-04, Impact Factor: 5.825

IJCSRR@ 2022

Www.ijcsrr.org

The overall assessment results also show that there are many staffs having different specialized skills from social workers. Due to objective factors, there are many health workers who are transferred to take responsibility for social worker jobs when the hospital establishes a social work department. And they do not have much knowledge in this field of social work. Therefore, they face many difficulties when implementing social work and other related activities.

Many hospitals have adopted strategies to recruit a person who has a social worker's background in hospitals. However, these people are young officials and they lack experience or basic knowledge about health or communication skills and how to deal-with patients. Therefore, it is necessary to have training courses with both medical staff and social workers in the hospital so that the work efficiency will be more effective.

\section{- The lack of coordination of departments negatively affects social worker's efficiency}

Social workers activities are specific and are implemented in the hospital environment so coordination with the rest of the medical staff plays an important role in the good implementation of their activities. Due to a lack of knowledge of social work, the cooperation activities implemented in hospitals have faced many difficulties in the past. That has created many difficulties and obstacles in the work of social work staff. However, with the strong development of social work as well as the change in awareness in this area, the coordination activities have become closer and efficiency has improved.

\section{- Characteristics of patients/clients negatively affect social worker's efficiency}

This is a factor affecting activity performance. The characteristics of each patient affect social work activities in the hospital which can be divided into two contents. First is in the hospital environment, many patients just finished medical examination so it is difficult to meet them immediately to determine if they need treatment. Second, the intervention time of social workers is not entirely decided by social workers but depends on the time of discharge. Therefore, if there are supports and interventions developed for patients but they leave the hospital so this effort is wasted.

In addition to their specific characteristics, some hospitals also have many special patient groups such as veterans or high-ranking officials ... so these VIP's has a great impact on the orientation of social work activities.

\section{DISCUSSION}

For social work in hospitals in Vietnam in general, this study proposes some general solutions as follows:

Firstly, the hospitals based on the Circular number 43/2015 and based on the actual situation of the hospital to establish a social work department directly under the hospital management or a social work group under the nursing room or general planning department. The establishment of social workrooms and teams in hospitals must include the task of providing support and counseling to solve problems of social work for patients and family members during the medical examination process as providing information, communication and law dissemination; mobilize funding; support medical staff; organizing charity activities, etc.

Secondly, universities in the health sector and some other schools need to provide social work training to ensure qualified human resources is available to meet the specific needs of the social work activity as required by Vietnamese society. However, there are no schools to train social workers to orientate them for the health sector specifically. The university and other school's training program should be designed to provide basic knowledge and skills on social work and health care. This training program will provide university-level human resources with basic science, basic medicine, epidemiology; having skills in social work with orientation on support, counseling, special health care for vulnerable and disadvantaged groups such as the elderly and the people with disabilities. Students will be equipped with different approaches to work well in the field of public health care from primary health care facilities to hospitals and counseling and health care services for outpatient as well as rehabilitation in the community.

Thirdly, the qualifications of social workers are inadequate as required. Therefore, it is necessary to train professional social workers at college, university, masters and doctoral degrees and develop training programs for each level of education. This is to meet the requirements of the country's socio-economic development process as well as the international integration process.

Fourthly, it is necessary to strengthen the staff and the network of providing social work services at all levels, from the central to the local and grassroots levels.

\section{CONCLUSION}

The project of developing a social work profession in the health sector from 2010 to 2020 was approved by the Ministry of Health in 2011. Until now, many hospitals have established their social workrooms to help patients. After the implementation period so 


\section{International Journal of Current Science Research and Review}

ISSN: 2581-8341

Volume 05 Issue 01 January 2022

DOI: 10.47191/ijcsrr/V5-i1-04, Impact Factor: 5.825

IJCSRR@ 2022

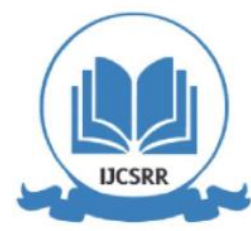

Www.ijcsrr.org

far, social policy in the health sector has appeared in several central and provincial hospitals. According to initial recognition, these activities have contributed to providing the information requested by patients and relatives of patients; connecting patients with services in and out of the hospital; support travel activities for disabled patients, the elderly and children; calling for the community's help for disadvantaged patients.

However, in parallel to the achieved milestones of the application of social work models in hospitals, the implementation of the project has many deficiencies such as the lack of understanding of the role of social workers in hospitals; lack of organizational mechanisms, quantity, and quality of human resources for social work in hospitals; communication work to propagate the project's activities. Therefore, it is necessary to improve the quality of social work activities in hospitals, contributing to solving urgent needs in health care, needing a long-term and appropriate development roadmap in parallel with raising awareness and commitment of implementation of leaders of medical examination and treatment facilities and officials in the health sector on the position, role and formation and development of the social work model.

\section{REFERENCES}

1. Ministry of Finance - Ministry of Labor - Invalids and Social Affairs (2011). Joint Circular No. 11/2011 / TTLT / BTCBLĐTBXH promulgating guidelines for management and use of funds for implementation of Decision No. 32/2010/QDTTG dated March 25, 2010, approved by the Prime Minister " Project on development of social work profession in Vietnam in the period 2011-2020".

2. Ministry of Health (2015). Circular No. 43/2015 / TT-BYT promulgating the tasks and forms of organizing the implementation of social work tasks in hospitals.

3. Ministry of Labor - Invalids - Social Affairs and Ministry of Home Affairs (2015). Joint Circular No. 30/2015 / TTLTBLĐTBXHBHV promulgating the provision of standard codes, professional titles for social work officers.

4. Ministry of Health (2011). Project on development of the social work profession in the health sector, period 2011-2020.

5. Ministry of Health (2011). Decision No. 2514 / QD-BYT of the Minister of Health approving the "Project on development of the social work profession in the health sector for the period of 2011-2020".

6. Ministry of Home Affairs (2010). Circular No. 08/2010 / TT-BNV issued titles and codes of social workers as government staff.

7. Ministry of Labor - Invalids and Social Affairs (2010). Circular No. 34/2010 / TT-BLĐTBXH promulgating regulations on professional standards of social workers' government officers.

8. Prime Minister (2010). Decision No. 32/2010 / QD-TTG approving "Project on development of the social work profession in Vietnam, period 2010-2020".

9. Tran Dinh Tuan (2015). Social work in hospitals', Workshop on Social Work in hospitals, Nha Trang.

10. Tran Cong Binh (2016). Development of social work profession in the health sector: Initial results, challenges, and recommendations, conference's materials "Social work in the field of health care", Dalat University.

11. Nguyen Quoc Giang (2016). Hospital social work - challenges to become a professional social work service, workshop document "Social work in the field of health care", Dalat University.

Cite this Article: Dr. Nguyen Trung Hai, Dr. Nguyen Thi Hoai An (2022). The Current Situation of Social Work Activities in Hospitals in Vietnam. International Journal of Current Science Research and Review, 5(1), 26-35 